\title{
REVISITING THE RESEARCH FIELD OF PRODUCT-SERVICE SYSTEMS DEVELOPMENT
}

\author{
Åsa Ericson \\ Luleå University of Technology \\ Luleå, Sweden \\ asa.ericson@ltu.se \\ Ola Isaksson \\ Volvo Aero Corporation \\ Trollhättan, Sweden \\ ola.isaksson@volvo.com
}

\author{
Tobias C. Larsson \\ Blekinge Institute of Technology \\ Karlskrona, Sweden \\ tobias.larsson@bth.se \\ Andreas Larsson \\ Lund University \\ Lund, Sweden \\ andreas.larsson@design.lth.se
}

\begin{abstract}
The research within the Product-Service Systems (PSS) field aims to support manufacturing industries' ability to provide value in terms of a service offer to its customers, simultaneously taking a more holistic approach to ecosustainability. The industrial idea of providing customer benefits in parallel with robust products is not new, yet equipping engineers to conduct innovation and applying a service perspective in the early design stages is noticed as fairly radical. The purpose in this paper is two-fold. First, to describe research efforts within the PSS field seen through our engineering design lenses, second, to explore and discuss plausible directions and by that identify "white spots" on the map, which may be seen as relevant directions for future research.
\end{abstract}

\section{INTRODUCTION}

The research field of Product-Service System (PSS) has over time become well known in Europe and Japan. The research efforts became evident at the end of the 1990's when the field started to crystalize into groups and networks of researchers having similar interest in targeting sustainability issues more profoundly. The EU funded thematic network Sustainable Product Development Network (SusProNet), which existed between 2002 and 2004 arranged a conference in which the diversity of the research community was manifested [1]. Initially, the concept of PSS stressed on linking hard and soft elements, e.g., technology and sociology, products and services, to target environmental problems systemically [1]. To approach the area to find holistic, i.e., systemic, solutions - the research must come from various fields, such as economics, management, eco-design, sociology, psychology, product design and engineering [1].

However, the linking of opposing elements also ensures a clash between fundamental ontological and epistemological beliefs, i.e. the way norms and research approaches by which research is conducted and directed becomes a debate itself. Just looking at the words in PSS, directly indicates two distinct rationalities, namely product that is grounded in a technical rationality, and service that is grounded in constructivist rationality. Simplified, technical rationality emphasize facts and quantitative measures, while constructivist rationality emphasize interpersonal social interaction as situations of learning, and subsequently also rely on qualitative assessments. The often cited authors Vargo and Lush [2] highlight that product development and service development are a matter of two totally different logics, and question if those can be managed simultaneously. Commonly, firms that develop and manufacture technical solutions regard services as after market activities [3], thus they are also developed after the product has been produced. While a common underpinning feature of PSS is an integration of the two early in the innovation and development process. This contradiction indicates a necessary paradigm shift for manufacturing firms when turning towards PSS, but also challenges research particularly when calling for cross-disciplinary and collaborative efforts. 
This paper addresses the PSS research field by applying two sorts of reasoning. First, we address PSS in hindsight, that is, we reflect on our own experiences from more than a decade of research efforts within the field. This journey is guided by relevant research from the field as a frame of reference. Second, we address PSS in foresight, that is, we make an inquiring dialogue on future research directions.

A delimitation of the paper is that although the origin of the PSS paradigm origins from industrial practices, it foremost provides a researcher's point of view. The industrial challenges rather describe the context of interest. Another delimitation is our perspective of engineering design, where the paper is an attempt to broaden and problematize established engineering practices. The aim of the paper is thus to pinpoint some areas of research that become of direct interest once adopting a PSS approach. A note should be done that this approach is chosen not to criticize, but to push the research frontier forward.

The disposition of the paper is that we start by introducing the concept of PSS and a discussion of its elements. This is done to map up some parts of the cross-disciplinary research area. After this we outline one stream of interest in the research field, namely industrial PSS. This is done to shed light on the aspects of collaboration and innovation within PSS. The paper ends with an outlook for the future.

\section{PRODUCT-SERVICE SYSTEMS}

The elements of product, service and system in PSS could benefit from a review. What is a product and what is a service? Two typical questions that have prevailed in early PSS research, and for some still prevail. Defining a standardized classification is archetypically related to technical rationality, but also within the service management field such efforts have existed. But, that debate petered out during the 1960s-80s without an agreement of a clear definition [4]; instead of counterproductive discussions, different descriptions are used.

If the term product is interpreted as in ISO standard definition, a product is the result of a process and is commonly a combination of commodities and services. So, whatever a company or an organization produces is a product, though we have to bear in mind that PSS originates from product development, as evident for example in the early network called SusProNet. Product development literature declares unison that there is no doubt that the interpretation of a product is something that is engineered, discrete and physical [6] when applying an engineering design perspective. Hence, from this perspective it makes sense to address product and service integration. Some persistently argues that it is wrong to include both words into PSS, but such attempts to researchers' warfare do not contribute to the good intentions of PSS and to the industrial need of support.

Nevertheless, it is still argued that the logic of service development and production is different from development and production of physical goods [2]- [5]. Settling that products are manufactured things, and services are different from that, is a good start for better understanding the core of PSS. Insights about the differences could actually ensure a successful integration of the both perspectives.

\section{Service Perspective versus Product Perspective}

A comparison between characteristics of products and services respectively builds up a basis for understanding the rationale for development and production. Grönroos [7] has highlighted the distinct characters and some of them are presented in Table 1 (adapted from [7], p.47).

\section{Table 1. CHARACTERS OF PRODUCTS AND} SERVICES

\begin{tabular}{ll}
\hline Products & Services \\
\hline Tangible & Intangible \\
Production and & Production, distribution \\
distribution separated & $\begin{array}{l}\text { and consumption } \\
\text { from consumption }\end{array}$ \\
A thinultaneous processes \\
Core value produced in & An activity or process \\
factory & Core value produced in \\
Transfer of ownership & No transfer of ownership \\
\hline
\end{tabular}

Vital knowledge searched for in the early research efforts were how the idea of PSS changed business models. In the early publications of PSS research the vision to go from customers buying and owning a product, to actually buying the function that the product could deliver was elaborated on. Also, insights from initial practice and the expectations on the changed business model were reported on [8].

During this period, a bulk of the efforts within our research community was on discussing 'function' and 'functional products', as talking about the perceived use one is looking for, coming from the reasoning on functional decomposition. The function in this case is not the technical performance as such, but rather the objective of the system; to provide a function, no matter the constitution of product or service.

The functional (total care) products as presented in Alonso-Rasgado et al [8] goes beyond such technical rationality, thus function is more related to the needs and value the user/customer are asking for. For PSS manufacturing firms, the challenge is not only to find the basic needs and to understand the customers' goals, but also to figure out how to provide that function in terms of a service. Major OEM's introduced pay-per-use oriented business models, while they effectively continued to develop their products irrespective of the business model. The term "Functional Product Development" was coined in order to address the product development community with the approach that user involvement and role during development needed to change. 
Services in manufacturing firms typically encompass maintenance, repair and overhaul, as well as they assure access to spare parts. That is, services are activities to keep the physical thing operable. While, service literature (and often also service companies) emphasize that a service perspective is set into action when everything the company does are developed as a total service offering. A total service offer is build up by packaging numerous of components, for instance, products, services, information and personal attention [7]. A key for providing total service offering is to develop the business relationships, with suppliers, sub-suppliers, user, customers, competitors and so forth. Further, the business relationships should sustain internal learning for the purpose to serve the customers better and to improve their performance [2]. For PSS, this means that engineers have to participate actively in user/customer meetings and the acquisition of user information, merely for the purpose to learn from users/customers. Moreover, the recognition of the different characters of products and services provide insights into the elements for PSS. From an engineering point of view this implicates that products should be developed while considering services (read maintenance, repair and overhaul), and vice versa. To understand the PSS vision, or the total service offering, we have to consider the meaning of the third word in PSS, namely system(s).

\section{Systemic Product-Service offerings}

The difference between systemic and systematic is discussed in systems science literature [9]. A systemic approach recognizes the world as complex interactions between different actors and contexts, where there exist different worldviews and thus different goals. To make sense of that 'mess' systemic, i.e., holistic, bottom-up inquires are done to understand the (social activity) system [9]. System is from this view nothing that readily exists, but something that is used by people to support better understanding. One interest is the interfaces between, different types of systems, for example humans and products and how these parts have an effect on the whole, i.e., the goal of the interaction. The term systematic relates to a system view where the system are perceived to exist, thus something can be labeled as 'a system' and accordingly it is given tangible features. Often, a systematic approach relates to breaking down the whole to understand the interacting elements. Shortly, systemic indicates a human and social view that aligns with a service perspective and systematic indicates a technical rationality as seen in systems engineering and aligns with a product perspective.

According to systems science theory the parts of a system are; input, a transformation process, output and feedback, and, a system has always a surrounding environment [9]. One important issue is that the transformation process is not a 'magic box' [9]. Thus the output has the same qualities as the input, yet its state is modified in the transformation. Literary speaking, if the input to the system is a product it cannot be transformed into a service. This is why companies' products and services (which all are different for different industries and branches) should be seen as two distinct elements that can be elaborated on to provide a systemic and holistic PSS offering [1]. That is, both products and services are feed into the development system, hence into the transformation process in order to create a PSS offering, which should target to support the user/customers fulfillment of their goals.

Patnaik [10] describes four categories of needs that in turn address four solution types (p. 52-53).

- Qualifier needs - represent needs that rises when existing solutions fails. Solving the solution (fixing the failure of the product) does not change the use of the product. People can describe and explain their qualifier needs in terms of suggestions of improvement of the product.

- Activity needs - represent needs that relate to specific activities that people like to perform. People are aware of activity needs and can describe them in terms of existing products.

- Context needs - represent needs that relate to a situation in which people live, work or operate. These need are more goal-oriented, might not be perceived by people and cannot be immediately articulated. But, as long as people are part of the context, the needs remain the same. Context needs drives solutions of new product families, where the solutions are not provided by the same company.

- Common needs - represent basic and universal needs, people are usually aware of them, but they routinely meet these needs by addressing activity or context needs. That is, these needs are hidden in routine work or workarounds. Activity or context needs are often means to a greater end, while common needs can be identified by understanding that greater ends.

In parallel, a PSS business model suggests three categories of solution directions [11]:

- Product-oriented - the ownership of the product is transferred and additional services are provided, e.g., the current type of manufacturing businesses.

- Use-oriented - no ownership transferred, provision of availability is considered a service, e.g., leasing or renting.

- Result-oriented - no ownership transferred, customers pay when using the solution, e.g., what is similar to functional (total care) products [8].

The product-oriented category aligns with needs categorized as qualifier needs for development of the product, and activity needs for the development of services. And the use-oriented category that describes a core service aligns with activity needs. For identifying and analyzing qualifier and activity needs, the contemporary marketing surveys and similar 
methods seem satisfactory, because users/customers can express their needs in relation to a product and/or a service. The result-oriented category, which could be seen as the optimized PSS solution, aligns with context needs and common needs. For this situation, the acquisition of user/customer information becomes a true challenge. There are two reasons for this. First, users/customers have trouble to describe situations and goals, in interviews and surveys, thus for engineers to get first hand experiences they have to meet and interact with user/customers in early stages of the development task. And, this interaction serves one purpose to learn from the users/customers, not to test and evaluate an existing product. Second, the result-oriented solution integrates both a technical rationality and constructivist rationality, and engineers have to possess such crossdisciplinary ability. Basically, engineering education and/or the engineering profession is not yet supporting this.

Further, PSS directs research in at least to sorts of business environments, namely business-to-business and business-toconsumer.

\section{INDUSTRIAL PRODUCT-SERVICE SYSTEMS}

Following Alonso-Rasgado et al [8] a number of engineering oriented research studies were undertaken in Sweden, and recently, the area has been brought up in the CIRP community. Industrial product-service systems (IPS ${ }^{2}$ ) is an application area that constitutes a domain of interest for the engineering design research community. Adding industrial to PSS is done to highlight that the community aims to contribute to manufacturing firms in business-to-business and business-toconsumer settings. IPS ${ }^{2}$ is manifested in yearly conferences, it started in 2009 and the forthcoming conference in 2012 is announced. Hence, IPS $^{2}$ as a platform for sharing research results is becoming established.

The basic scope of the conferences is to address research within the broad area of industrial PSS, where the distinct conferences add a specific theme. In 2011 the theme life-cycle engineering was added to the core of PSS, but contributors were invited to discuss the vision, state of the art and innovations within those areas. Further, the conference aims to attract both industrial and academic actors possessing diverse experiences of various business activities that support PSS. By this broad and encompassing scope the conferences could be interpreted as cross-disciplinary, and could have the potential to attract researchers from several areas. Overall, researchers from the domains of engineering and manufacturing are attracted by the topics of the IPS $^{2}$ conferences. Only a few contributions from social science, service research and industrial design can be seen in the 2009-2011 conferences.

The focus on manufacturing creates a common view of a product development process and its stages. That is, a typical product development process, with its early stages of planning, scoping and concept generation, and subsequent later stages of detail design, production and product launch [6], provides a taken for granted perspective. Another, assumption that guides product development is that the early stages are vital, because it is in these stages that the product's characteristics are settled. An analysis of all published contributions to the IPS ${ }^{2}$ conferences, 2009-2011, showed that through out the years an extensive number of papers clearly stated to focus early stages, see Table 2. Further analysis showed that none of the papers described what steps that constituted the early stages, and many of the total number of the papers did actually address early stages, but this was not explicitly stated. The visualisation of product development as consisting of stages also describes a process that has a clear starting and ending point. Yet, prompting a common view, such an established and taken for granted view on process models might hamper PSS realization.

Table. 2. IPS ${ }^{2}$ PAPERS 2009-2011.

\begin{tabular}{ccc}
\hline Year & $\begin{array}{c}\text { Total no. of } \\
\text { papers }\end{array}$ & $\begin{array}{c}\text { Percentage of papers } \\
\text { focusing early stages }\end{array}$ \\
\hline 2011 & 60 & $33 \%$ \\
2010 & 69 & $38 \%$ \\
2009 & 51 & $43 \%$ \\
\hline
\end{tabular}

Service development processes does not apply process models that have early and later stages, rather they prescribe a frontline (what the customer sees and experience) and backstage (not visible for customers, support backup for executing service activities) view [5]. Thus, such description evokes a visualization that a service provider should start at a point close to the customer, and from that position also taking the customers' view on the company [7]. Or, as Grönroos [12] suggests, instead of focusing what existing products can offer customers, the firm should figure out what it can do to its customer in form of a total service offering. Though, the idea of suggesting a change in early stages when the product is in a state of flux, the specification is not yet fixed, opens up for new and innovative solutions.

\section{PRODUCT-SERVICE INNOVATION}

The concept of PSS is from the initial efforts aligned with the intentions to provide added value. The role of services in such value adding relationship was recognized as important, and not only tied to products. Now, it was stated, added value comes from technological improvements, intellectual property, product image, brand names, aesthetic design and styling. All these are non-material aspects of the product [13]. However, such service and value perspective build on the interpretation that the product is, maybe not the only value carrier, but still the value-generating item. By this, the early stages of product development still benefit from activities where the product is put in the center. A consequence of this orientation is that it promotes a status quo where only incremental improvements of the product and its supporting services arise. Business-as-usual is one model included into the PSS business models, i.e., 
product-oriented solutions [11], but it can be questioned if this is a topic for future PSS engineering design research efforts. Recently, the value proposition focus in PSS development has increased, and by that the result-oriented model [11] gains increased interest. Also the idea of services as activities has recently changed within the service management field. Grönroos [14] answered the question 'what is service?' (note: not what is $\underline{\boldsymbol{a}}$ service?):

\section{"Service is to facilitate and support another party's practices (processes, activities; physical, mental) in a way that helps this other party achieve its goals in life or business"}

Just replacing the word 'service' with 'providing value' the perspective of product-service innovation could be discerned. Within this perspective, the idea of acknowledging the integration of the elements of products and services to sustain innovative and new solutions based on people's basic and universal needs is at the heart. Thus, such perspective puts people/users/customers in a focal position. One engineering practice that aligns with this approach is Design Thinking [15]. Roughly, design thinking change traditional product development by contributing to both mindset and process. Two basic stances that build up mindset are empathy and integrative thinking [15]. Empathy, the ability to imagine the world from multiple perspectives and taking a 'people first' approach, provide an ability to meet both explicit needs (as for example qualifier and activity needs [10]) and latent needs (as for example context and common needs [10]). By this, both product and service innovation are supported. Integrative thinking, the ability to see all of the significant, but also contradictory aspects of a problem situation, prevents a onesided analysis of either/or choices [15]. Instead of focusing on trade-offs (either/or), solutions consisting of both product and service innovation can come true.

PSS development is recognized as urging for better and more appropriate approaches to manage continuous and radical innovation in order to fulfill customer perceived value. Tukker and Tischner [16] concludes that two important pillars are valid for PSS development:

1. The final functionality that the user/customer are seeking to fulfill should be the starting point of development. This is instead of starting with existing products that (initially seems to) fulfill the stated functionality.

2. Collaboration and value chain position should be continuously elaborated on based on a 'greenfield' mindset. This is instead of taking existing structures, routines and positions for granted.

Lush and Vargo [17] provide a conceptual vocabulary for the transition from goods-dominant logic (G-D) to servicedominant logic (S-D). Some key terminologies are presented in Table 3 (adapted from [17], p. 286). Besides, indicating a change in marketing, the vocabulary provides insights for the direction for building new and necessary abilities for PSS development.

Compared to the product-, use- and result-oriented categories [11], the G-D logic relates to the product-oriented model, transitional concepts relates to the use-oriented model, and S-D logic relates to the result-oriented model. At this stage, the challenges for manufacturing firms can be distinguished. Turning towards PSS and S-D logic calls for a profound change in the practice on multiple abstraction levels. In such change management the old models does not become totally obsolete over night, but has to be manage throughout several years. This means that several business models have to be considered, subsequently the scooping, planning and concept generation for the product have to take several possible directions into consideration [18]. One challenge for PSS research is to progress tools and methods to support engineers' transition process in going from product-orientation to serviceorientation.

Table. 3. CONCEPTUAL VOCABULARY.

\begin{tabular}{|c|c|c|}
\hline $\begin{array}{l}\text { G-D logic } \\
\text { concepts }\end{array}$ & $\begin{array}{l}\text { Transitional } \\
\text { concepts }\end{array}$ & $\begin{array}{l}\text { S-D logic } \\
\text { concepts }\end{array}$ \\
\hline Products & Offerings & Experiences \\
\hline Feature/attribute & Benefit & Solution \\
\hline Value-added & Co-production & $\begin{array}{l}\text { Co-creation of } \\
\text { value }\end{array}$ \\
\hline $\begin{array}{c}\text { Profit } \\
\text { maximization }\end{array}$ & $\begin{array}{c}\text { Financial } \\
\text { engineering }\end{array}$ & $\begin{array}{c}\text { Financial } \\
\text { feedback/learning }\end{array}$ \\
\hline Price & Value delivery & $\begin{array}{c}\text { Value } \\
\text { proposition }\end{array}$ \\
\hline $\begin{array}{l}\text { Equilibrium } \\
\text { systems }\end{array}$ & $\begin{array}{l}\text { Dynamic } \\
\text { systems }\end{array}$ & $\begin{array}{c}\text { Complex } \\
\text { adaptive systems }\end{array}$ \\
\hline Supply chain & Value chain & $\begin{array}{c}\text { Value-creation } \\
\text { network }\end{array}$ \\
\hline $\begin{array}{c}\text { Product } \\
\text { orientation }\end{array}$ & $\begin{array}{c}\text { Market } \\
\text { orientation }\end{array}$ & $\begin{array}{c}\text { Service } \\
\text { orientation }\end{array}$ \\
\hline
\end{tabular}

Over time in the engineering design research community of PSS, the originally and paramount vision of sustainability has, in our view, been sidelined. However, providing services is not per default environmental friendly [13]. Though, PSS innovation, which is more connected to the value generating process and is based upon careful studies of people behavior, might provide a sound approach.

Through the recent advances within the design and manufacturing research community, as well as the emerging 
organization of industrial application areas, the PSS area may become the tool that links value and sustainability perspectives.

Increased manufacturing life cycle responsibility, limitations in natural resources and competition/differentiation based on users perception of using product rather than owning products - all drive the same behavior.

Manufacturing organizations need to combine both products and services in combination, and need to adopt their way of developing solutions accordingly,

\section{OUTLOOK FOR FUTURE PSS RESEARCH}

This paper has outlined a view of PSS development research effort. We do not claim that this is the 'true' and only view of PSS research; rather we have not left our own backyard. Though, if we, metaphorically speaking, are standing on our toes in our backyard, looking at the horizon, we can discern some interesting future research areas.

Product development processes and service development processes is one area that needs further attention. Here the acknowledgement of technical rationality and constructivist rationality has to be a guiding principle for research. Rationality is the base for peoples cognition, and directs what abilities we consider valid. Approaches that enhance and support people's capability to 'de-learn' and 're-learn' are needed, also approaches for systemic reasoning is needed. Such research would benefit from the areas of, e.g., systems thinking, phycology, sociology and pedagogics. In parallel, the engineering education has an established curriculum to support technical problem solving, but pay little attention to the more creative and innovative efforts needed for investigating the user/customers problem situations which should be the starting point for PSS development.

Research methods that bridge the ontological and epistemological gap between technologists view and the service research view is another area. Overcoming such differences certainly would benefit PSS development research. Currently, the research community is divided, even though most PSS researchers admit that cross-disciplinary research would be best. A breakthrough in this area would probably also become good cases for investigating how to support similar changes in practice where marketing and engineering have to close the gap.

In addition, research to bridge the contextual barriers between different disciplines and communities is needed. Sharing knowledge is becoming a key ingredient for adopting new theories and practices.

The issue with intangible/qualitative and tangible/ quantitative elements in services and products is yet another vital area. In order to engineer and manufacture products, facts and measurements are necessary. Further, when developing products reducing ambiguity as soon as possible is part of the process. Since services should be considered as a value proposition process including several parties, which actually means include people with different worldviews, different goals and different perceptions, ambiguity becomes part and parcel of PSS development. Research to find out how to enhance the communication yet still preserving ambiguity, and thus innovation opportunities, in PSS development is delimited, This area would benefit from ethnography and qualitative studies of the contemporary knowledge sharing activities. Approaches, methods and tools that support PSS development are an expressed need from manufacturing industry.

Finally, the issue of not transferring ownership highlights a business situation where tighter cross-company collaboration is needed. One line of research here is how to share knowledge without leaking intellectual properties. Another line of research is how to manage those property rights that remain distributed in the extended enterprise needed for PSS provision.

\section{ACKNOWLEDGMENTS}

The financial support from VINNOVA, and the Foundation for Strategic Research through the ProViking research programme is gratefully acknowledged.

\section{REFERENCES}

[1] Mont, O. and Tukker, A. 2006. Product-Service Systems: reviewing achievements and refining the research agenda. Editorial in Special Issue of Journal of Cleaner Production. 14, pp. 14511454.

[2] Vargo, S.L. and Lusch, R.F. 2004. Evolving to a new dominant logic for marketing. Journal of Marketing, 68, pp.1-17.

[3] Normann, R. 2001. Reframing business: when the map changes the landscape. John Wiley and Sons Ltd, Chichester.

[4] Gummesson, E. 2002. $2^{\text {nd }}$ edition. Total relationship marketing - marketing management, relationship strategy and CRM approaches for the network economy, Butterworth Heineman, Cornwall.

[5] Edvardsson, B., Johnson, M. D., Gustafsson, A., and Strandvik, T. 2000. The effects of satisfaction and loyalty on profits and growth: products versus services. Total Quality Management. 11 (7), pp. 917-927.

[6] Ulrich, K.T. and Eppinger, S.D. 2008. Product design and development. McGraw-Hill Inc.

[7] Grönroos, C. 2000. Service management and marketing: a customer relationship management approach. Wiley, Chichester.

[8] Alonso-Rasgado, T.. Thompson, G. and Elfström, B-O. 2004. The design of functional (total care) products. Journal of Engineering Design, 15 (6), pp. 515-540.

[9] Checkland, P. 1999. Systems thinking, systems practice: a 30 year retrospective: soft systems methodology. John Wiley \& sons, Ltd. Chichester. 
[10] Patnaik, D. 2004. System Logics: Organizing Your Offerings to Solve People's Big Needs. Design Management Review, summer, pp. 5057.

[11] Tukker, A., van den Berg, C. and Tischner, U. 2006. Product-services: a specific value proposition. In: Tukker, A. and Tischner, U. (editors). New business for old Europe: Product-Service Development, Competitiveness and Sustainability. Greenleaf Publishing, UK, pp. 22-34.

[12] Grönroos, C. 1996. Relationship marketing: strategic and tactical implications. Management Decision, 34 (3), pp. 5-14.

[13] Mont, O.K. 2002. Clarifying the concept of product-service system. Journal of Cleaner Production, 10, pp. 237-245.

[14] Grönroos, C. 2011. Keynote at ECIS 2011 conference, Alto University, Finland, June 9-11. http://www.ecis2011.fi/wp-
content/uploads/2011/04/2011GrönroosKeynote 2.pdf. Accessed 2012-02-17.

[15] Brown, T. 2008. Design thinking. Harvard Business Review, June 2008, pp. 84-92.

[16] Tukker, A. and Tischner, U. 2006. Note from the Field: Product-Services as a Research Field: Past, Present and Future. Reflections from a Decade of Research. Journal of Cleaner Production 14, pp. 1552-1556.

[17] Lusch, R.F. and Vargo, S.L, 2006, Servicedominant logic: reactions, reflections and refinements, Marketing Theory, 6 (3), pp. 281288.

[18] Ericson, Å., Larsson, T. and Åström, P. Functional product innovation: reaping the benefits of simulation driven design. 2007. Knowledge sharing and collaborative engineering. KSCE 2006. Boumedine, M. and Touzet, C. (editors). ACTA Press. 